\title{
MÍMESIS DA LINGUAGEM EM WALTER BENJAMIN
}

Sergiano Silva

\begin{abstract}
RESUMO
O presente trabalho objetiva discutir o conceito de mímesis a partir da filosofia da linguagem de Walter Benjamin. Em 1916 o autor já esboçava uma interpretação da mímesis da linguagem baseada em sua leitura do livro Gênesis exposta no texto Sobre a linguagem em geral e a linguagem dos homens. Porém, somente na década de 1930 ele irá definir mais precisamente o que seria essa mímesis da linguagem, agora tendo como panorama um mundo já decaído e pobre em experiências mágicas. Veremos, por fim, que a "capacidade mimética" seria outra forma de rearticular o elo perdido entre os nomes e as coisas, transformando-se ela mesma em uma singular experiência.
\end{abstract}

Palavras-chave: Walter Benjamin; Mímesis; Linguagem; imitação.

\section{MIMESIS OF LANGUAGE IN WALTER BENJAMIN}

\begin{abstract}
This paper aims at discussing the concept of mimesis through Walter Benjamin's language philosophy. In 1916, the author had already outlined an interpretation of language's mimesis, based on his reading of the book Genesis, in the text "On language as such and on the language of man". Nevertheless, it was only in the 1930s that he would define more accurately this language's mimesis, having as panorama a fallen world also poorer of magical experiences. Lastly, it is argued that the "mimetic faculty", as a form of re-articulate the missing link between names and things, transforms itself into a singular experience.
\end{abstract}

Keywords: Walter Benjamin, Mimesis; Language; imitation 


\section{Introdução}

“Já então”, escreve Gershom Scholem a respeito de sua amizade com Walter Benjamin por volta de 1916, "ele se preocupava com as ideias sobre a percepção como uma leitura (ein Lesen) nas configurações da superfície com a qual o homem pré-histórico acolhia o mundo ao seu redor, especialmente o céu" (SCHOLEM, 1975, 80). Segundo o estudioso cabalista, dessas ocupações surgirão as reflexões expostas no texto Doutrina da semelhança (Lehre vom Ähnlichen); porém, apenas, dezessete anos depois, em 1933, ele escreveria o texto que deveria se tornar sua "nova teoria da linguagem" (BENJAMIN, 1974-1985, G. B. IV,163), em alusão à "primeira" exposta no trabalho Sobre a linguagem em geral e a linguagem do homem (Über Sprache überhaupt und über die Sprache des Menschen) ${ }^{1}$. Dessa mesma época também data uma "reelaboração" daquele texto, resultado de pequenos retoques quando Benjamin tentava redigir uma cópia para Scholem (BENJAMIN, G. B. IV, 1995, 183): Sobre a capacidade mimética (Über das mimetische Vermögen).

Supõe-se que a diferença entre ambos os textos foi condicionada pelo impacto que o segundo deveria produzir no destinatário, ou seja, Scholem; daí que, segundo Winfried Menninghaus, diante do primeiro, o novo trabalho recua em seus pontos e em suas terminologias explicitamente "místicas" (MENNINGHAUS, 1980, 61). É certo, pois, que no final do segundo trabalho já se anuncia a superação completa da magia na linguagem (BENJAMIN, 1974-1989, G. S. II, 213), porém mesmo que tais passagens místicas tenham sido suprimidas não é menos provável que a "face de Jano" benjaminiana mostrasse, mesmo que tensionada, o seu lado materialista mas também "metafísico", visto que Scholem apurava naquela segunda nota a ele enviada a "carência da mais leve insinuação de uma teoria materialista da linguagem" (SCHOLEM, 1975, 260). Ou seja, se Benjamin resolveu depurar os resquícios místicos no segundo texto em prol de um teor desvinculado da magia, o resultado não foi absolutamente o esperado, pelo menos na percepção do amigo.

\footnotetext{
${ }^{1}$ Designaremos esse trabalho por Sprachaufsatz.
} 
De resto, o enfoque na semelhança e na mímesis está ainda intimamente ligado ao seu Sprachaufsatz de 1916 como também ao ensaio sobre a tradução. Ocorre que Doutrina da semelhança e Sobre a capacidade mimética não envolvem nenhuma interpretação da mítica sagrada e nem referências a autores místicos como ocorre no texto do primeiro Benjamin, mas antes abordam a linguagem na sua materialidade, sua fisionomia, por assim dizer; é exatamente neste sentido que ele encontra o debate acerca da naturalidade da palavra e, portanto, da teoria onomatopeica.

Assim, Benjamin sucumbiu ao entusiasmo em torno da leitura de um estudo de Rudolf Leonard intitulado A palavra (Das Wort), sobre o qual, em carta a Scholem de 25 de outubro de 1932, ele informa que "apesar do seu fundamento teórico equivocado", "trata-se de uma teoria onomatopaica da palavra" (BENJAMIN, idem, G. B. 140). O que há de fundamental neste trabalho pode ser resumido em uma única proposição de Leohnard citada por Benjamin na redação da Doutrina da semelhança: "Toda palavra é - toda a linguagem é - onomatopaica" (BENJAMIN, G. S. II,, 1974-1989, 207). A partir dessa provocação ele esboçará os textos que analisaremos ${ }^{2}$.

Para chegar a esse ponto Benjamin propõe já de início na Doutrina da semelhança a defesa de uma tarefa e de uma tese. A primeira expressa que a compreensão das semelhanças tem importância fundamental para o esclarecimento do saber oculto e que para alcançar tal compreensão seria necessária a "reprodução dos processos que produzem essa semelhança” (BENJAMIN, G. S. II, 1974-1989, 204). Haveria assim dois meios constitutivos e distintos dessa "capacidade" (Fähigkeit) de produzir semelhanças. Com efeito, em primeiro lugar, "a natureza produz semelhanças" (idem, 204); Benjamin aponta o mimetismo (Mimikry), i. e. a forma de adaptação de certos animais e plantas que, como forma de defesa, por exemplo, imitam o ambiente ao redor. Mas o autor sequer se atém neste dado que parece ser óbvio o bastante. Para ele, interessa constatar o outro meio desta capacidade de produzir semelhança.

\footnotetext{
${ }^{2}$ Seguimos a proposta de Menninghaus de trabalhar os dois textos de modo unívoco, detendo o que há de comum neles, assinalando, quando for o caso, as suas disparidades.

Doutorando em História Social da Cultura na Pontifícia Universidade Católica do Rio de Janeiro (PUC- RIO). Residente em Rio de Janeiro - RJ. Email: sergiano silva@hotmail.com
} 
De certo modo, seguindo a proposição aristotélica ${ }^{3}$, ele afirma que o homem é o detentor do mais alto grau de produzir e, principalmente, de reconhecer semelhanças, na medida em que não há nenhuma de suas funções elevadas que não esteja impregnada por essa força. Eis o manto do saber oculto que todo ser carrega, assim, em termos ontogênicos, como quando uma criança "imita" tanto seres animados como inanimados (casa, mesa, etc.). A resposta à questão sobre a necessidade dessa aprendizagem ${ }^{4}$ "natural" de se comportar mimeticamente Benjamin apanha na suposição de uma história humana daquela capacidade, ou seja, ele vai buscar, em termos filogenéticos, a razão do domínio das semelhanças.

\section{A semelhança entre nós}

Ora, atesta-se como tese benjaminiana a qual nos referimos que, ao contrário dos antigos, cujo círculo da existência (Lebenskreis) era majoritariamente determinado por semelhanças e pelas suas percepções através da relação análoga entre micro e macrocosmo, o homem contemporâneo estaria "pobre" e fragilizado demais para se conscientizar daqueles episódios "cotidianos" em que reina o semelhante. É certo que esta constatação aponta também para a condição de que as experiências modernas deslocam as "verdadeiras" experiências, mas aqui Benjamin não se prolonga nesta questão e nem mesmo tenta explicar o porquê dessa fragilidade, confirma-a apenas. Sua questão se restringe à possibilidade de saber se houve uma extinção da faculdade mimética ou, pelo contrário, se de fato ocorreu apenas sua transformação.

Como a resposta seria naturalmente esta última, ele cita a astrologia como exemplo dessa mudança, visto que as constelações seriam configurações sensíveis

\footnotetext{
${ }^{3}$ Pensamos na passagem da Poética que aponta: 'A imitação é natural ao homem desde a infância, sendo uma das vantagens sobre os animais mais baixos que ele seja a criatura mais imitativa do mundo e, primeiramente, aprende pela imitação." ARISTÓTELES. The complete works of Aristotle. Princeton, New Jersey: Princeton University Press, 1984, v. 2, p. 2318, 1448 b5.

${ }^{4}$ No livro Infância em Berlim por volta de 1900 Benjamin exemplifica poeticamente o caráter didático das semelhanças a fim de compreender certas palavras: "A tempo aprendi a me mascarar nas palavras, que, de fato, eram como nuvens. $O$ dom de reconhecer semelhanças não é mais que um fraco resquício da velha coação de ser e se comportar semelhantemente. Exercia-se em mim por meio de palavras. Não aquelas que me faziam semelhante a modelos de civilidade, mas sim às casas, aos móveis, às roupas." BENJAMIN, Walter. Rua de mão única. São Paulo: Brasiliense, 1993, p. 99. G. S. IV 261.
}

Doutorando em História Social da Cultura na Pontifícia Universidade Católica do Rio de Janeiro (PUC- RIO). Residente em Rio de Janeiro - RJ. Email: sergiano silva@hotmail.com 
(sinnfällige Gestaltung) que constituiriam objetos de caráter mimético estabelecidos no horóscopo, posto que a posição dos astros acarretaria em um efeito que por sua vez determinaria uma dada peculiaridade nos homens. Em um fragmento intitulado Sobre a astrologia (Zur Astrologie), que pode ser considerado outra variante dos textos aqui tratados, apesar de escrito um ano antes, em 1932, Benjamin afirma: "De fato, deve-se considerar esta imitação (Nachahmung) a instância única que proporciona à astrologia o caráter de experiência" (BENJAMIN, G. S. VI, 1974-1989, 192). Isto porque os eventos celestes poderiam ser imitados, o que dava aos povos antigos as condições de alcançar a harmonia cósmica do mundo através dessas analogias ou correspondências. Aliás, isto se torna evidente quando Benjamin chama o horóscopo de "totalidade originária" (originäre Ganzheit).

No Sprachaufsatz Benjamin atenta ao fato de que após o pecado original a linguagem pura, totalizante e originária decaiu junto com os habitantes do paraíso; um dos significados dessa queda seria que "o homem transforma a linguagem em meio...e com isso a transforma, pelo menos em parte, em mero signo" (BENJAMIN, 2011,68 ), ou seja, ela não tem mais a imediatidade (medium) da língua originária mas passa, de uma vez por todas, a carregar um significado, algo que vem de fora dela mesma. Supõe-se que, como objetos de interpretação e de leitura, os astros, como tudo o que existe, teria sua linguagem, sua essência linguística atrelada à experiência humana. Em outras palavras: a totalidade originária do horóscopo seria senão a linguagem originária rearticulada como meio, embora não como medium pois neste último a relação "amorosa" homem-natureza remetia à condição paradisíaca perdida na qual os nomes eram o índice desse casamento. O horóscopo é apenas uma aproximação possível da essência primeva das coisas, uma tentativa de reatar aquela união; o arrolamento de signos do zodíaco seria, finalmente, ao contrário dos signos linguísticos decaídos do período pós lapsariano, a expressão do que há de mais verdadeiro, i. e. da revelação divina ou mesmo cosmológica a nos contar nossos destinos e particularidades pessoais.

A intenção de Benjamin vai além, pois o horóscopo é uma marca. Ela é forjada num momento único no qual as semelhanças entre micro e macrocosmo se entrelaçam, a saber, o momento do nascimento. O recém-nascido detém a posse total desse dom da semelhança porquanto seja ele um "ajustamento" (Anbildung) 
material das ordens cósmicas. A partir destas clarificações podermos afirmar que 0 nascimento e o signo zodíaco do recém-nascido são tanto um sinal (Zeichen) quanto uma mancha (Mal) - a marca.

Em um texto intitulado Signo e mancha, de 1917, Benjamin afirma que o signo implica numa relação estritamente pessoal enquanto a mancha, por seu lado, se apoia na dimensão temporal; visto que o signo é uma impressão de fora para dentro e a mancha, ao contrário, se destaca de dentro para fora, esta última designaria um medium (BENJAMIN, 2011, 83). A mancha, no entanto, está associada à culpa (o rubor da vergonha, por exemplo) ou à inocência (como as chagas de Cristo), ou seja, ela "desintegra a personalidade", enquanto no signo a particularidade ascende a um grau de distinção maior. Essas reflexões são o pano de fundo para que o autor estabeleça a pintura (Malerei) como um medium dela mesma, pois ela "é uma tal mancha (Mal), sendo que não conhece nem fundo nem língua gráfica”.

Porém, questionamos: o que isso implica no que temos discutido? Tudo, na medida em que para Benjamin a pintura, "ao ser nomeada, é relacionada a alguma coisa que ela não é", a uma força que "é a palavra da língua que - invisível como tal, e revelando-se apenas na composição - se estabelece no medium da linguagem pictórica" (idem, 86). O nome ou o título da obra é a confluência ou a correspondência de mediuns da linguagem: o medium da palavra e o medium pictórico. O recém-nascido, portanto, é tal qual um quadro que, quando nomeadomanchado, estabelece a harmonia do medium da linguagem, assim como, enquanto signo conjurado pela astrologia, erige sua personalidade. A semelhança e a linguagem alcançam aqui o mais alto grau de imiscuidade.

Voltando ao ponto em que paramos. A referência ao recém-nascido também é importante para Benjamin em dois sentidos; primeiro porque ele não é somente a concreção da semelhança mas, igualmente, a sua confirmação perfeita posto que, segundo o Sobre a astrologia, "mesmo hoje, diante de todos, [o recém-nascido] demonstra, ao longo dos primeiros anos de vida, o gênio mimético mais extremo no aprendizado da linguagem" (BENJAMIN, G. S. VI, 1974-1989, 193). Em segundo lugar, a partir de seu próprio corpo, ele é a prova materializada do que hoje raramente se percebe, a saber, de que existe também uma semelhança além do próprio sensível. Daí que Benjamin cunha o tortuoso, relativo e "incompreensível" - 
segundo ele próprio - conceito de "semelhança não sensível" (unsinnlichen Ähnlichkeit): "Ele [o conceito de "semelhança não sensível"] significa que não mais possuímos em nossa percepção (Wahrnehmung) aquilo que outrora tornava possível falar de uma semelhança entre uma constelação e um humano" (BENJAMIN, G. S. II, 1974-1989, 207). Entretanto, ele admite o aprendizado da língua como a invocação do gênio mimético. Afinal ainda persistiria um cânone no qual se encontra os resíduos daquelas forças: a linguagem.

Constata-se, no entanto, que, não obstante essa relação entre a faculdade mimética e a linguagem já plenamente notada em Origem do drama barroco alemão (Ursprung des deutschen Trauerspiel) ${ }^{5}$, as reflexões de Benjamin não se restringiam ao "campo mais familiar (i.e., sensível) da semelhança". Para as velhas teorias onomatopaicas, "na origem da linguagem coube ao comportamento imitativo (nachahmendem Verhalten) o lugar de elemento onomatopeico" (idem, 207). Aqui podemos visar um panorama, visto que da cansativa descrição e do que foi dito até agora, poderíamos seguir em torno de algumas hipóteses e questões que ajudarão a incluir essas reflexões dentro da construção benjaminiana de um conceito de linguagem totalizante (pura).

\section{Mimesis e linguagem}

A primeira dúvida que nos vem à cabeça se relaciona à afinidade entre essas últimas afirmações e os primeiros trabalhos de Benjamin sobre a linguagem. Afinal, que ligação existiria entre essa propalada e mesmo "atrevida" - segundo a definição do próprio (BENJAMIN, G. B IV, 1995, 214) - teoria acerca da capacidade imitativa e aquelas páginas do Sprachaufsatz? Ora, há razões suficientes para acreditarmos que esse ensaio de 1933 seria uma saída ou uma resposta às inquietações suscitadas ainda em 1916. Ele precisaria de alguma fundamentação para se arriscar a pensar a linguagem como ainda detentora de certo poder criativo, mesmo que para isso tivesse que reabilitar a sua outrora leitura negativa da mímesis, como explica Beatrice Hanssen ao afirmar que ele "revisou totalmente sua própria avaliação inicialmente negativa da mímesis como um modo não autentico do ser,

\footnotetext{
${ }^{5}$ Ver a seção em que Benjamin discute a obra de Joachim Ritter G. S. I 397-9 
cuja falsidade formou a chapa contra a qual a pureza da linguagem anteriormente adquiriu forma" (HANSSEN, 2004, 66).

Benjamin, assim, sustenta que a capacidade de produzir semelhanças teria migrado para outros círculos da experiência. Nestes textos sobre a semelhança ele fecha o arco que esboçara há quase duas décadas: a linguagem "abandonou", escreve ele em 1916, "a sua própria magia imanente para reivindicar expressamente seu caráter mágico, de certo modo a partir do exterior" (BENJAMIN, 2011, 67). A chave dessa magia exterior é precisamente a capacidade mimética que a partir de agora seria a única forma de mediação mágica na qual a imediatidade despontaria seu frágil poder de criação ${ }^{6}$. Porém, questiona-se, não podemos chamar essa força de imediata visto que ela é externa à linguagem. Certamente, mas ela é uma imediatidade, por assim dizer, mediada. Expliquemos.

Em primeiro lugar, quando, no Sprachaufsatz o autor escreve sobre as significações do pecado original, admite que a linguagem se transforma "pelo menos em parte" (idem, 68) em mero signo. Em segundo lugar, e por conseguinte, a imediatidade perdida se torna mediada mas não completamente. Como explica nosso filósofo, ela não é mais plenamente interior - embora parta também da interioridade - senão que necessita da apreensão externa, de modo que é na experiência que o mundo pós-babélico deve procurar a relação imediata perdida. Ela deve ser diversa da experiência mundana e prosaica, sendo, ao contrário, um momento especial único, como o nascimento do recém-nascido, um instante $(N u)$ no qual a revelação se expressa num clarão.

Não à toa essa experiência sempre recairá na formação da linguagem. Pois, mesmo depois da queda, ela não deixará de ser uma criação. Se, de uma vez por todas, não lhe caberá mais o dom da nomeação divina através do qual Adão selava o produzido enquanto producente, restar-lhe-á o dom da imitação como criação. $O$ assemelhar é o dom profano de nomear; em outros termos, se o suposto mundo da creatio ex nihilo desmoronou, de suas ruínas só será possível a imitação como criação "inventiva", digamos "artística" pois que humana, distinta da "imitação não

\footnotetext{
${ }^{6}$ Assim como o poder messiânico também se caracterizaria pela fragilidade, de acordo com a tese II: ("eine schwache messianische Kraff"). G. S. I 694.
} 
criativa" de que se fala no ensaio de 1916. Ela será a única capacidade de nomeação possível.

Enquanto a linguagem no Sprachaufsatz se inclui na esfera da criação, aqui ela ocupa um lugar específico. Não será o do significado, mas algo que the é previamente solicitado, i. e. a semelhança. Como não se pode mais criar do nada, a linguagem adentra noutra atividade, a de provocar, a de tributar nova experiência. Não é origem mas reelaboração da linguagem. Eis o que seria a percepção da semelhança, assim vista como nova criação a partir da linguagem. Criação agora externalizada (mediada) mas ainda assim imediata na medida em que a semelhança ocorre apenas num instante, como lemos na Doutrina da Semelhança: "Sua percepção, em todos os casos, está ligada a um relampejar (Aufblitzen). Ela transcorre, talvez possa ser alcançada novamente, mas, ao contrário de outras percepções, não pode ser mantida” (BENJAMIN, G. S. II, 1974-1989, 206).

A efemeridade e a fugacidade através das quais a semelhança se exprime seriam outro modo de imediatidade cujo "lado mágico da linguagem" (idem, 208), assim como na tradução, seria uma indicação objetiva dirigida para a linguagem mesma como totalidade (aquela totalidade originária), ou seja, a produção da semelhança na linguagem é o "aroma", a "essência", a substância a partir da qual as "coisas se encontram e se relacionam", embora "não diretamente" como antes (idem, 209).

\section{Mímesis ou cópia?}

Daí decorre outra questão. Seria esta capacidade mimética mera imitação? Vários comentadores apontam que claramente essa força não pode ser reduzida à imitatio $^{7}$. Márcio Selligman-Silva sustenta que "a visão naturalista da linguagem baseia-se em semelhanças sensíveis e não em semelhanças não-sensíveis. Se seguíssemos à risca esta categoria benjaminiana, não se poderia falar de uma simples mímesis", aqui entendido no sentido de imitativo (SELIGMANN-SILVA, 1999, 11). Jeanne Marie-Gagnebin, por sua vez, aponta ser inútil procurar em Benjamin

\footnotetext{
${ }^{7}$ Escusa alertar que não abordaremos aqui uma "história" ou arqueologia do conceito de mímesis e da leitura deturpada que, desde o Renascimento, associa-o à imitatio. Esse trabalho já fora realizado, por exemplo, pela obra de Luiz Costa Lima.
} 
uma similitude entre palavras e coisas baseada na imitação: "Saber ler o futuro nas entranhas do animal sacrificado ou saber ler uma história nos caracteres escritos sobre uma página significa reconhecer não uma relação de causa a efeito entre a coisa e as palavras ou as vísceras, mas uma relação comum de configuração." (GAGNEBIN, 1993, 81)

Menninghaus diz que de modo algum se trata da reprodução de supostos objetos; ao invés, a "capacidade de produzir semelhanças espontaneamente [pertenceria] sempre a um dom de compreensão receptiva de 'correspondências mágicas"” (MENNINGHAUS, 1980, 64. Sublinho nosso). Assim, também, segundo Hanssen, o fato de "humanos serem dotados de capacidade mimética significa que eles possuíram a habilidade não apenas de reconhecer (recepção) mas de produzir similaridades (espontaneidade)" (HANSSEN, 2004, 66). Ora, essa capacidade receptiva é, a seu modo, uma reelaboração da palavra divina no nome a qual alude Benjamin no Sprachaufsatz: "No nome a palavra divina não permanece criadora; ela tornou-se em parte receptiva (empfangend), mesmo que receptiva na linguagem" (BENJAMIN, G. S. II, 1974-1989, 150). O qualitativo dúbio, que pode significar ou receptividade ou concepção (Empfängnis) no sentido de fecundação estabelece assim a linguagem como uma atividade historicamente vital, com uma espécie de "vida" própria. Se essa concepção não é mais imanente ao nome, ela poderá sê-lo na exterioridade da experiência. É uma "espontaneidade e concepção" (idem, 150) que reside apenas numa relação de reciprocidade e de mediação externa, o que não a reduz a mediação pura, afinal ela tem, sim, seu "instante" próprio, mágico e imediato - o que confirma nossa hipótese dessa capacidade mimética ser uma imediatidade mediada.

Por outro lado, a concepção do nome babélico ou do nome profano terá sempre um lado construtivo que desmente qualquer imputação de imitação. Na verdade, como insinuamos nos comentários acima, essa imitação não é outra coisa senão a criação, e com isso vemos que nela se impõe um conceito geracional que também remete à teoria da energia (potencialidade) aristotélica. Não sem razão Benjamin também situa o nascimento do recém-nascido como momento ou instante crucial para entender o que ele quer dizer por capacidade mimética: esta não quer simplesmente adentrar o mundo da experiência através da reprodução 
perfeitamente "semelhante" entre micro e macrocosmo senão que possui a força de assimilar uma relação existente entre os diversos círculos da existência humana e o que está ao seu redor.

A imitação na concepção benjaminiana é coerente com o que ele afirmou sobre a linguagem. Esta é claramente um ser ativo cuja vitalidade não esmorece na língua dos homens, ela recua e enfraquece, é certo, mas guarda-se para germinar diante do instante fatal; ela se adéqua ao fato de perder sua magia imediata, possibilitando o dom de expor sua atividade de outro modo, i. e. através da geração de semelhanças diferenciadas. Uma receptividade ativa, que concebe. Assim, ela é perfeitamente mímesis, ou seja, de acordo com Luiz Costa Lima, produtora de uma diferença a partir de um horizonte de semelhança (COSTA LIMA, 1980, 71) . $^{8}$

$\mathrm{Na}$ verdade, não há como compreender essa noção de imitação sem notarmos que, por trás dela, encontra-se um fundamento preciso: a semelhança é pura e simplesmente a expressão de correspondências a partir do dom de compreendê-las como tal. Por isso, para explicá-la, Benjamin lança mão desse termo em algumas passagens. Ora as semelhanças são "correspondências naturais" (natürlichen Korrespondenzen) (BENJAMIN, G. S. II, 1974-1989, 205), ora "correspondências mágicas" (magischen Korrespondenzen) (idem, p. 206), ora, por fim e mais explicitamente, "correspondências não sensíveis" (idem, 208) (unsinnlicher Korrespondenzen). Mais uma vez, a correspondência aqui não é o "ajustamento" perfeito de cópias e protótipos mas, ao contrário, a constatação de uma relação entre cosmos distintos, como se estivessem num mesmo medium que num momento podem se completar amorosamente, rememorando o casamento originário que foi marca da linguagem adâmica. Se desde a queda do Paraíso a linguagem é regida pela lógica que lhe é externa e não mais interna, a produção de semelhança é o modo profano e "cotidiano" que ela adotou para "literalizar" sua magia não mais metafórica através do mundo exterior (MENNINGHAUS, 1980, 19).

\footnotetext{
${ }^{8}$ A partir de Costa Lima em Mimesis e modernidade: "Na realidade efetiva do produto mimético, i. e., em sua circulação, realiza-se a combinação de uma semelhança, que funciona como o precipitador do significado que nele se aloca, e de uma diferença, o que não 'cabe' naquele significado e, então permite a variação interpretativa." LIMA, Luiz Costa. Mimesis e modernidade. Rio de Janeiro: Graal, 1980, p. 71.
}

Doutorando em História Social da Cultura na Pontifícia Universidade Católica do Rio de Janeiro (PUC- RIO). Residente em Rio de Janeiro - RJ. Email: sergiano silva@hotmail.com 


\section{Mímesis e percepção}

A espontaneidade na produção da semelhança não existiria caso ela não fosse reconhecida. A pobreza do homem moderno reside exatamente no fato de ele não deter mais os meios e a experiência para perceber tais semelhanças. Então, a doutrina das semelhanças basear-se-ia 1) na produção destas semelhanças e 2) no seu reconhecimento, ou nas palavras de Benjamin, na "conscientização" delas. Ela gira em torno da percepção como concepção, ou seja, como conhecimento. Por um lado, ela aponta para a maiêutica socrática, que tem na figura do nascimento ou do parto a configuração do saber. Ora, por outro lado, aqui ressoa o debate que se inclui no tortuoso caminho da teoria do conhecimento e do que seria conhecido por séculos como a querela dos universais ${ }^{9}$, partindo das concepções platônicas e aristotélicas.

Assim, temos o exemplo do Teeteto de Platão: o conhecimento (episteme) adviria da sensação? Nesse indefinível diálogo sobre a natureza do conhecimento, Teeteto lança sua primeira tese ao afirmar exatamente que o conhecer "não é nada mais do que sensação (aisthesis)" ou percepção (PLATÃO, 2001, 49, 151e) ${ }^{10}$. Sócrates nega veementemente que o saber provenha desta fonte argumentando que ela estaria ligada à concepção tanto de Protágoras (o mundo é a medida do homem) quanto a de Heráclito, segundo a qual tudo é movimento. Logo, assenta-se que, diante da multiplicidade de sensações que percebemos ao mesmo tempo, seria preciso uma unidade que as mediasse; a alma seria essa "única ideia" que se constituiria num "ponto de convergência delas todas, por meio da qual, usada como instrumento, percebemos todo o sensível" (idem, p. 99, 184d). Aferrados apenas nesta primeira tese discutida no diálogo, podemos afirmar que, assim como para Platão a impressão não produz nenhum conhecimento visto que ela não atinge o ser através do qual se apreende a verdade (HENNIGFELD, 1994, 56), a sensação pura também para Benjamin não é o meio único de alcançar a semelhança, daí o seu

\footnotetext{
${ }^{9}$ Tal querela seria o pano de fundo do prefácio epistemo-crítico do Trauerspielbuch, isto de acordo com Tiedemann. TIEDEMANN, Rolf. Études sur la philosophie de Walter Benjamin. Trad. : Rainer Rochlitz. Paris : Actes Sud, 1987, p. 19.

${ }^{10}$ A tradução do termo conduz diretamente ao termo percepção, como ele é traduzido em outras línguas, como no alemão (Wahrnenhmung).

Doutorando em História Social da Cultura na Pontifícia Universidade Católica do Rio de Janeiro (PUC- RIO). Residente em Rio de Janeiro - RJ. Email: sergiano silva@hotmail.com
} 
conceito de "semelhança não sensível" e sua crítica às teorias onomatopeicas que se baseiam preponderantemente na sensibilidade ${ }^{11}$. Então, perguntaríamos, o que seria essa percepção necessária para reconhecer a semelhança e tornar-se consciente dela?

Responderíamos, obviamente, que Benjamin intenta alargar e estender o sentido das teorias onomatopaicas para além da sensibilidade e, por isso, ele adianta um novo conceito de percepção que talvez seja uma das chaves para entender conceitos ulteriores como o de aura. Ela é ainda sensação, mas não se restringe à impressão primeira individualizada. A percepção está intimamente vinculada a uma superfície, mas também a algo além, como se vê num fragmento intitulado Über Wahrnehmung in sich (Sobre a percepção em si): "Percepção é leitura. Legível é apenas o fenômeno na superfície" (BENJAMIN, G. S. VI, 1974$1989,32)$. Só se lê o que está na superfície, por isso que Scholem nota em suas memórias que "a origem das constelações como configurações na superfície celeste era, como afirmava [Benjamin], o começo da leitura e da escrita" (SCHOLEM, 1975, 80). Se é possível ler apenas o que está na superfície, a semelhança precisa de um suporte material para se manifestar: ou nas estrelas ou nos corpos ou na linguagem, mais exatamente, na escrita. Benjamin nomeadamente aponta a escrita como o fenômeno mais evidente para se perceber (i.e. ler) a "semelhança não sensível", talvez melhor ainda do que a língua falada.

Na Doutrina, ele exemplifica a "semelhança não sensível" na escrita: "Deste modo, a letra beth tem o nome de uma casa" (BENJAMIN, G. S. II, 1974-1989, 208), determinando que a semelhança implica que as palavras diversas de todas as línguas são, apesar das diferenças gráficas e vocais, semelhantes ao seu significado, o que se percebe no caso da imagem da letra hebraica exemplificada pelo autor $(ב)^{12}$. Ou seja, mesmo uma letra remete a uma harmonia da língua, configurando uma reelaboração da totalidade perdida.

\footnotetext{
${ }^{11}$ Com base nessa suposição, Benjamin já havia anos antes fundamentado sua crítica ao sistema kantiano, cujo conceito de experiência aloja-se sob a preponderância da consciência empírica. G. S. II 163.

${ }^{12}$ A referência, como sempre em Benjamin, é ao alfabeto hebraico. Beth é a sua segunda letra, sua variante em relação ao alfabeto de outros povos semíticos.

Doutorando em História Social da Cultura na Pontifícia Universidade Católica do Rio de Janeiro (PUC- RIO). Residente em Rio de Janeiro - RJ. Email: sergiano silva@hotmail.com
} 
Benjamin chama esse suporte (Träger), essa imagem e o conjunto dela nas frases, de semiótico: "A conexão de sentido das palavras e frases é o suporte necessário para que apareça, como um raio, a semelhança” (BENJAMIN, G. S. II, 1974-1989, 213). Mas importa aqui a imagem (fisionomicamente) semelhante ao referente para ser apreendida como fenômeno. A escrita não é tão somente um poço de significados, mas também de semelhanças; ou antes, o significado aqui é obliterado diante da semelhança que aponta em todas as línguas a mesma significação, i. e. em direção a uma intenção objetiva, a uma harmonia das línguas, como também a indica a tradução. Assim, na exigência de uma superfície para a leitura da percepção, Benjamin aqui relativiza, como no final do Sprachaufsatz, o lado puramente instrumental da linguagem, a fim de demonstrar a letra também como superfície de semelhanças: "Todo mimético da linguagem é antes uma intenção fundada que se manifesta apenas em algo estranho, precisamente o semiótico e o comunicativo da linguagem como seu fundo" (BENJAMIN, G. S. II, 1974-1989, 208) ${ }^{13}$. Assim como, a partir da leitura das vísceras do animal ou da posição dos astros, pode-se entrever a semelhança entre os cosmos, na letra escrita essa força seria o único meio possível de ela ser percebida pelos homens modernos - afinal nós a lemos.

Essa relação intrínseca entre percepção, semelhança e imagem desembocaria naturalmente numa reflexão sobre o símbolo, aquilo que Benjamin abordaria justamente na sua tese de habilitação. Não à toa, em seu esquema para o Origem... ele anota que o símbolo, a percepção e o conhecimento estão relacionados respectivamente ao símbolo em si, ao simbolizante e ao simbolizado. Em um fragmento, lemos: "A percepção refere-se ao símbolo" (BENJAMIN, G. S. VI, 1974-1989, 32). Em outro intitulado Notizen zur Wahrnehmungsfrage (Notas sobre a questão da percepção), ainda: "Existem três configurações na superfície absoluta: signo, percepção e símbolo" (idem, 32). Signo e percepção podem ser lidos embora

\footnotetext{
${ }^{13}$ Benjamin continua afirmando que o texto literal da escrita seria o fundo a partir do qual se pode formar o quebra-cabeça (Vexierbild). A referência diz respeito à grafologia e o fato de ela dar a perceber, tornar consciente as características da pessoa que escreve: "A mais nova grafologia ensinou a reconhecer, nas imagens manualmente escritas ou quebra-cabeças, o que o inconsciente oculta dentro delas." G. S. II 208. A relação de Benjamin com a grafologia pode ser observada na resenha entusiasmada sobre o livro de Anja e Georg Mendelson, Der Mensch in der Handschrift (III 135-9); também sobre o tema, Scholem notava o "interesse intensivo" sobre esse campo já em idos de 1915. Ver SCHOLEM, Gerschom. Op. Cit., 1975, p. 23.
}

Doutorando em História Social da Cultura na Pontifícia Universidade Católica do Rio de Janeiro (PUC- RIO). Residente em Rio de Janeiro - RJ. Email: sergiano silva@hotmail.com 
o símbolo não. Portanto, já é notoriamente evidente que, a partir dessas reflexões anotadas desde a época do Sprachaufsatz, Benjamin não tinha outra intenção senão pensar numa configuração artística e é neste sentido que o problema da linguagem/semelhança o interessava em demasia, pois nele se encontra a origem do que é expressivo, distinguindo o comunicativo e o simbolizante da arte.

\section{Considerações finais: mímesis, arquivo e obra de arte}

A linguagem como atividade produtora (como poiesis) - eis o que se pode entrever da teoria da mímesis de Benjamin. Ela é também o fundo do qual nenhuma teoria sobre a obra de arte jamais deve escapar. Esse passo fora dado já no final do Sprachaufsatz quando ele declara que persiste uma função simbólica na linguagem pós-queda. Ou seja, sobrevive ainda um resíduo da magia da imediatidade adâmica nas palavras. Esses pontos (sobrevivência e residualidade) clarificam toda a concepção de mundo benjaminiana, e não por coincidência já podem ser notados desde o "primeiro Benjamin".

Assim, esse lado simbólico da linguagem configura-se como um "arquivo" ou "depósito" cujo poder será - assim como em Proust - casualmente deflagrado num instante: é exatamente isso o que o "segundo Benjamin" (supostamente "materialista"), aquele que escreve a Doutrina da semelhança, tem em mente quando teoriza esse poder de produzir semelhanças na "associação" entre o cosmos e entre "o falado e o intencionado (Gemeinte) mas também entre o escrito e 0 intencionado e o falado e o escrito" (BENJAMIN, G. S. II, 1974-1989, 208). Como nesta última relação reside o maior fator de percepção possível aos homens modernos desvirtuados do poder total de apreensão, a escrita constituiria o arcano dessa magia: "A escrita torna-se, assim, ao lado da língua, um arquivo de semelhanças não sensíveis, de correspondências não sensíveis" (idem, 213). Antes um medium totalizante, na medida em que sua imediatidade era imanente à própria expressão, a linguagem dos homens constitui ainda um medium cuja imediatidade é mediada pelo suporte, embora não possa ser considerada como instrumentalizada de todo pois nela ainda persiste o resíduo simbólico, através do qual só poderá se expressar enquanto magia ou poesia -em determinado lugar especial: na própria linguagem 
escrita, aquela mesma que se identifica com a queda, pois, como expressa a cabala, mesmo nos detalhes do mal o divino aponta o caminho para a redenção.

Para quem se detém nas notas e nos fragmentos de Benjamin para a redação desses textos observará que a sua preocupação é evidentemente a relação da linguagem com a obra de arte. Essas notas tornam claro que o seu interesse se baseava na relação dessa linguagem e da poesia, da obra de arte em geral, enquanto "criação" ou artefato humanos. Prova disso é que, nas anotações ao texto Capacidade mimética, referindo-se à "poesia atual", ele confessa a desmagicização da linguagem na poesia de Brecht: "Linha de desenvolvimento da linguagem: o divórcio entre função mágica e profana do falar é liquidada em favor da última... Direção a uma linguagem carente de todos os elementos mágicos: Scheebart, Brecht” (BENJAMIN, G. S. II, 1074-1989, 956). É curioso que a relação mágica da obra de arte a partir da magia da linguagem e de sua permanência ou nãodecadência perpassa todos os seus escritos "estéticos", seja qual for sua "fase". Sobre a aura, por exemplo, ele questiona em suas notas à Doutrina das semelhanças: "Os astros, com seu olhar a partir da distância, são o fenômeno originário da aura?" (idem, p. 958). Aí está a chave para entender as categorias fundamentais de Benjamin trabalhadas no campo da arte, todas lançando a hipótese de que linguagem e obra são estruturalmente equivalentes.

\section{REFERÊNCIAS}

BENJAMIN. Walter. Gesammelte Schriften. Herausgegeben von Rolf Tiedemann und Hermann Schweppenhäuser. Frankfurt am Main: Suhrkamp Verlag, 1974-1989.

. Gesammelte Briefe. Herausgegeben von Christoph Gödde und Henri Lonitz. Frankfurt am Main: Suhrkamp, 1995.

Escritos sobre mito e linguagem. Trad.: Susana Kampff Lages e Ernani Chaves. São Paulo: Duas Cidades: Editora 34, 2011.

Rua de mão única. São Paulo: Brasiliense, 1993

GAGNEBIN, Jeanne Marie. "Do conceito de mímesis no pensamento de Adorno e Benjamin" in:__ Perspectivas, São Paulo, 16, 1993. 
HANSSEN, Beatrice. Language and mimesis in Walter Benjamin's work In The Cambridge Companion to Walter Benjamin. (Ed.) David S. Ferris. Cambridge, UK: Cambridge University Press, 2004

HENNIGFELD, Jochem. Geschichte der Sprachphilosophie: Antike und Mittelalter. Berlin: Walter de Gruyter, 1994.

LIMA, Luiz Costa. Mimesis e modernidade. Rio de Janeiro: Graal, 1980

MENNINGHAUS, Winfried. Walter Benjamins Theorie der Sprachmagie. Frankfurt am Main: Suhrkamp, 1980

PLATÃO. Teeteto. Trad.: Carlos Alberto Nunes. Belém: UFPA, 2001.

SELIGMANN-SILVA, Márcio. Ler o livro do mundo: Walter Benjamin: romantismo e crítica poética. São Paulo: lluminuras: Fapesp, 1999

SCHOLEM, Gerschom. Walter Benjamin: Die Geschichte einer Freundschaft. Frankfurt am Main: Suhrkamp, 1975

TIEDEMANN, Rolf. Études sur la philosophie de Walter Benjamin. Trad. : Rainer Rochlitz. Paris : Actes Sud, 1987 